\title{
Forage inevitability in early dairy calf raising: nature manages
}

\begin{abstract}
Modernization in dairy production has made fundamental changes in calf raising and nutritional management programs. Such changes do not always accord with natural rhythms of ruminant eating behaviour and rumen bio-processing and fermentation of different foods. Quality forages contain functional compounds such as novel flavonoids with health implications for early calf development and later productive longevity as a super cow. Forages in optimal physical and chemical forms should be accommodated in young calf diets to optimize growth and health.
\end{abstract}

Keywords: calf, rumen, physiology, flavonoids, bioprocessing
Volume 2 Issue 3 - 2015

\author{
Akbar Nikkhah \\ Department of Animal Science, University of Zanjan, Iran
}

Correspondence: Akbar Nikkhah, Chief Highly Distinguished Professor, Faculty of Agricultural Sciences, University of Zanjan, National Elite Foundation, Iran, Tel +98 243505 280I, Fax +98 243505 3202,Email anikkha@yahoo.com,nikkhah@znu.ac.ir

Received: March 12, 2015 | Published: May 28, 2015

\section{Discoveries, critiques, and discussion}

The modern ruminant farming has unfortunately kept distance from natural patterns of ruminant life and rumen physiology. ${ }^{1}$ Notably, to expedite reasonable rumen development of effective microbial fermentation and early calf growth, it has been merely stressed and recommended that young calf diets should contain easily and moderately fermentable starches, namely cereal grains, and quality proteins such as soybean meal. ${ }^{2}$ However, no evolutionary and special emphasis has been made on the essentiality of feeding physically and chemically functional forages in optimal forms and mixtures to neonate and young calves. Forage has conventionally, and in many cases indeed imperfectly, been offered free choice and separate from concentrate. Due to such a component offer of forage and concentrate and also the lengthy form of forages, calves normally would not be eager to consume them. This is not healthful since quality forages, particularly in leaves and soft plant pieces, contain a variety of functional compounds such as flavonoids that help rumen fermentation develop healthfully as it does in nature with natural patterns, without compromising calf growth and wellbeing. ${ }^{3}$

Ruminants have evolved to calve in nature and thus calves have evolved to be nourished and nursed in nature or the foremost mother. Nature welcomes and feeds immature ruminants with fresh and quality forages that contain different sets of physical and chemical structures, from cellulose and hemicelluloses to polyfructans, oligomannans, pectins, starches, sugars and organic acids along with vitamins and minerals. These compounds are received by calves in orchestrated forms and ratios, complementing cow milk as the central source of indispensible nutrients, so that rumen microbial growth and development occur in harmony with calf's own tissue growth. As such, no major stresses are imposed to the young growing ruminant.

However, the above-mentioned bioprocesses are largely disturbed, if not becoming futile, in many modern ruminant production systems. ${ }^{3-5}$ The problems are exacerbated when overlooking such a natural ruminant life style becomes a practice by fallaciously recommending no such fresh and physically fine roughages in concentrates that are fed to young growing calves during early weeks of life. It must be underlined that since young calves are not capable enough to effectively consume long forages and overly coarse particles, to ensure adequate ingestion of functional materials (e.g. flavonoids) present in quality roughages, the forage must be finely and mechanically bioprocessed to permit uniform mixing with concentrates. Offered so, palatability and particle size will be favoured by young calves. Meanwhile, adequate physically and chemically effective forage fibres can reach the rumen to ensure timely and healthy microbial growth and fermentation.

\section{Implications}

Calf nutrition, especially in first few weeks and months of age, must follow natural patterns in eating and ruminating behaviours. Mere or maximal calf dependence on highly energetic easily fermentable cereal and protein meal-based concentrates must no longer be the gold goal. Alongside, optimally processed quality forage, particularly leaves and soft stems, may be effectively fed to young calves either free choice or likely more successfully mixed with concentrate. This ensures adequate and timely administration of functional physical and chemical compounds towards healthy and high-merit cow-generating calf nutrition and raising management.

\section{Acknowledgements}

Acknowledged thankfully are the Ministry of Science Research and Technology, National Elite Foundation, and University of Zanjan for supporting the author's global programs of optimizing science edification in the new millennium.

\section{Conflict of interest}

Author declares that there is no conflict of interest.

\section{References}

1. Nikkhah A. Ruminant chronophysiological management: an emerging bioscience. Open Access Anim Physiol. 2011;2011(3):9-12.

2. NRC (National Research Council). Washington, DC: Nutrient Requirements of Dairy Cattle. 7th Rev ed. Natl Acad Sci. 2001

3. Yaghoubi SMJ, Ghorbani GR, Rahmani HR, et al. Growth, weaning performance and blood indicators of humoral immunity in Holstein calves fed supplemental flavonoids. J Anim Physiol Anim Nutr. 2008;92(4):456-462.

4. Nikkhah A. Chronophysiology of ruminant feeding behavior and metabolism: an evolutionary review. Biol Rhythm Res. 2013;44(2):197-218.

5. Nikkhah A. Time of Feeding an Evolutionary Science. Germany: Lap Lambert Publishing, GmbH \& Co. KG; 2012. 